\title{
Evidence-Based Prenatal Management in Cases of Congenital Diaphragmatic Hernia
}

\author{
Alex Sandro Rolland Souza \\ Professor Fernando Figueira Integral Medicine Institute (IMIP) \\ Recife, Pernambuco \\ Brazil
}

\section{Introduction}

Congenital diaphragmatic hernia $(\mathrm{CDH})$ is the most common defect of the diaphragmatic muscle that separates the thoracic cavity from the abdominal cavity. This malformation allows part of the abdominal structures (intestinal loops, stomach and liver) to herniate into the thoracic cavity, hampering the normal development of the lung and resulting in abnormalities in cardiac function (Santos et al., 2008; Johnson, 2005).

This defect may result in severe repercussions even in the prenatal period, with a high rate of intrauterine or early neonatal mortality, principally due to pulmonary hypoplasia (Santos et al., 2008; Johnson, 2005). Prenatal diagnosis is possible; however, in less severe cases diagnosis may be reached later, beyond the neonatal period at more advanced ages, although this is less common (Santos et al., 2008; Johnson, 2005; Bronshtein et al., 1995; Lewis et al., 1997; Koziarkiewicz \& Piaseczna-Piotrowska, 2011).

With the advancement of medical science, survival of these newborn infants has improved; nevertheless mortality remains high (van den Hout et al., 2011; Okuyama et al., 2011). Alternative intrauterine therapies have been studied, with the best results in recent years having been found with the use of fetoscopy (Deprest et al., 2011; Luks, 2011; Peralta et al., 2011). An immense arsenal of treatments for the early neonatal period has also been studied, improving the life of these newborn infants (Henderson-Smart et al., 2011; Mugford et al., 2011; Moyer et al., 2011; Finer \& Barrington, 2011).

It is therefore prudent to invest in new diagnostic techniques and therapies for application in the prenatal period in an attempt to permit normal lung development and a consequent improvement in the care provided to these patients.

\section{Epidemiology}

The incidence of congenital diaphragmatic hernia varies greatly depending on the origin of the data, whether resulting from studies conducted pre- or postnatally or based on surgical studies. In surgical studies, data losses occur due to pregnancy termination, miscarriage, prenatal mortality and immediate neonatal mortality. The neonatal incidence rate is around 1 in 5,000 to 1 in 3,000, whereas the prenatal incidence rate is 1 in 2,000 (Santos et al., 2008; Johnson, 2005). 
The most common site of $\mathrm{CDH}$ is posterolateral and this malformation is more commonly found in males, in a proportion of 2 to 1 . Unilateral $\mathrm{CDH}$ is more common than bilateral, with unilateral hernias being more likely to occur on the left side (Santos et al., 2008; Johnson, 2005). A significant association has also been found with other congenital malformations, aneuploidies and genetic syndromes (Santos et al., 2008; Johnson, 2005; Zaiss et al., 2011; Stressig et al., 2011).

\section{Anatomy}

The diaphragm is the musculotendinous structure interposed between the thoracic and abdominal cavities. It is dome-shaped, its convex upper surface forming the floor of the thoracic cavity and its concave lower surface forming the roof of the abdominal cavity. The muscular portion is located at the peripheral part, being affixed to the lower thoracic wall along its entire circumference, and divided into three portions: sternal, costal and lumbar. The fibers extend from the peripheral part, converging at the center of the muscle and forming the central tendon, where the foramen of the inferior vena cava is situated to the right of the median plane (Fregnani et al., 2005; Sociedade Brasileira de Anatomia, 2001).

The sternal portion of the diaphragm, the smallest part, is attached to the back of the xiphoid process. The fibers of the costal portion are found laterally to the sternal portion. Together, the costal and sternal portions form a small triangular gap on both sides, the base of which faces forwards, with the apex facing backwards towards the central tendon. These gaps are known as the right sternocostal triangle of Morgagni and the left sternocostal triangle of Larrey (Fregnani et al., 2005; Sociedade Brasileira de Anatomia, 2001).

The costal portion comprises the muscular fibers of the lateral region and the anterior portion of the diaphragmatic muscle. The lumbar portion is located in a posterior position, where the esophageal and aortic hiatuses are found. In the posterolateral region, between the costal and lumbar portions, there is a triangular gap on both sides, the base of which is directed downwards to the quadratus lumborum muscle, while the apex is directed upwards to the tendinous center. These gaps are known as the right and left lumbocostal triangles (posterolateral), also known as Bochdalek's triangles (Fregnani et al., 2005; Sociedade Brasileira de Anatomia, 2001).

\section{Classification}

The diaphragmatic hernia is classified in accordance with the site of the malformation, reflecting its embryologic origin. There are four types of diaphragmatic hernia (Santos et al., 2008; Johnson, 2005):

- Posterolateral defect or Bochdalek hernia, the most common type and responsible for $85-90 \%$ of cases detected neonatally. The malformation occurs through the pleuroperitoneal canal and may be unilateral or bilateral. The left side is the more common site, corresponding to $80 \%$ of cases. This phenomenon is probably related to the fact that fusion occurs later on the left side than on the right side. Bilateral hernias are the least common, constituting approximately $5 \%$ of all cases.

- Parasternal defects or Morgagni hernias are rare, constituting 1-2\% of all cases of CDH. They occur in the anterior segment of the diaphragm, between the costal and sternal origins of the organ, on the right. 
- Malformations of the septum transversum, located at the midline, occur due to defects in the central tendon of the diaphragm.

- Hiatal hernias are less important clinically. They are the result of a congenitally wide esophageal orifice; however, they do not permit the passage of abdominal organs into the thoracic cavity.

\section{Embryology}

The diaphragm is formed between the $4^{\text {th }}$ and $12^{\text {th }}$ weeks of pregnancy from the septum transversum, the pleuroperitoneal membrane, the dorsal mesentery of the esophagus and from muscle growth. This structure is totally formed at 8-12 weeks and its fusion is complete before the bowel returns to the abdominal cavity (Arraez-Aybar et al., 2009; Johnson, 2005).

The septum transversum is a mesodermal mass that is formed from the fusion of the third, fourth and fifth myotomes, representing the primordium of the central region of the diaphragm. A caudal migration occurs when the heart descends into the thorax, growing dorsally from the ventrolateral wall of the diaphragm (Arraez-Aybar et al., 2009; Johnson, 2005).

The pleuroperitoneal membrane located midway between the two sides grows ventrally, attaching to the septum transversum anteriorly and to the dorsal mesentery of the esophagus posteriorly, closing parallel to the region of the veins (Arraez-Aybar et al., 2009; Johnson, 2005).

The right hemidiaphragm consolidates earlier than the left, which, together with the position of the liver on the right side, may explain why the Bochdalek hernia is more common on the left side, whereas parasternal hernias are more common on the right, due to the fact that the pericardium protects the left side, hampering the development of hernias on this side (Arraez-Aybar et al., 2009).

\section{Etiopathogenesis}

No environmental etiological factor has been identified as being potentially responsible for $\mathrm{CDH}$ in humans. However, $\mathrm{CDH}$ has been induced experimentally with the use of thalidomide, vitamin A deficiency, polybromobiphenyls and nitrofen (Arraez-Aybar et al., 2009). There are reports in the literature that smoking and radiofrequency may constitute possible causes of $\mathrm{CDH}$ (Caspers et al., 2010; Yamagami et al., 2011); however, further studies need to be conducted to confirm these hypotheses.

The occurrence of $\mathrm{CDH}$ is normally sporadic; nevertheless, familial $\mathrm{CDH}$ has already been reported (Narayan et al., 1993). Another study suggested the possibility of alterations in the genome of patients with congenital diaphragmatic hernia, either isolated or non-isolated (Wat et al., 2011). Plenty of evidence of a genetic link in some cases but this is beyond the scope of this chapter.

Two hypotheses have been raised to attempt to explain the origin of diaphragmatic hernias: as a failure in fusion or as a primary defect (Johnson, 2005). It has been suggested that when an abnormality occurs in the development of the diaphragm during the embryonic phase, a 
malformation occurs in the fusion of the pleuroperitoneal membranes, causing a persistent fault. The abdominal organs then fail to be covered by the peritoneum. Consequently, the hernia sac will also fail to be covered by the peritoneum, as occurs in cases of Bochdalek hernia. This is why it is considered a false hernia (Arraez-Aybar et al., 2009).

On the other hand, in the primary defect, which occurs in the fetal phase when the pleuroperitoneal hiatus has closed but muscle migration is incomplete, the defect is located in the diaphragmatic muscle. Therefore, the increase in abdominal pressure may push the abdominal viscera through the thoracic cavity and consequently the hernia sac will be covered by the peritoneal membrane, as occurs in the case of parasternal hernias. These cases are considered true hernias (Arraez-Aybar et al., 2009). Exceptionally, as the result of diaphragmatic aplasia and of a persistent pericardial-peritoneal shunt, the hernia may occur without a sac, an extremely rare condition known as peritoneopericardial diaphragmatic hernia (Arraez-Aybar et al., 2009; Kessler et al., 1991).

\section{Natural history}

A diaphragmatic hernia is a congenital malformation occurring in the first trimester of pregnancy; however, the time at which the hernia sac can be identified has yet to be determined. There are well-documented cases in which a prenatal ultrasonography scan performed in the second trimester had been normal but a diagnosis of diaphragmatic hernia was made at a later scan or even at birth (Johnson, 2005; Bronshtein et al., 1995). The time of $\mathrm{CDH}$ diagnosis has been evaluated in relation to perinatal prognosis. Survival rates are better in cases diagnosed at birth or in the third trimester compared to cases in which diagnosis is made in the early prenatal phase (Johnson, 2005; Manni et al., 1994). However, when cases diagnosed prenatally were compared with nondiagnostic sonographies (falsenegatives), survival was similar in both groups (Johnson, 2005; Lewis et al., 1997). The reason for this herniation occurring earlier or later has yet to be satisfactorily explained in embryological terms (Johnson, 2005).

Pregnancies in which the fetus has a congenital diaphragmatic hernia may be complicated by polyhydramnios, which predisposes the patient to premature delivery. $\mathrm{CDH}$ may be associated with other congenital abnormalities, aneuploidies and genetic syndromes, conditions that affect the survival rate (Johnson, 2005).

The necessary conditions for adequate pulmonary development are: adequate intrathoracic space, normal fetal respiratory movement and the presence of a normal amount of amniotic fluid. If one of these conditions is deficient during the canalicular phase of pulmonary development (from the $17^{\text {th }}$ to the $26^{\text {th }}$ weeks of pregnancy), pulmonary hypoplasia will probably occur (Johnson, 2005; Burri, 1984). Therefore, principally as a result of reduced intrathoracic space, pulmonary hypoplasia is common in cases of $\mathrm{CDH}$ and constitutes a significant cause of mortality in these patients (Johnson, 2005; Santos, et al., 2008).

\section{Prenatal diagnosis}

Detailed ultrasonography is the most important method of prenatal diagnosis, since it permits a meticulous evaluation of the $\mathrm{CDH}$ and of any associated congenital abnormalities, in addition to following up the condition during pregnancy (Johnson, 2005; Santos, et al., 
2008). Fetal morphological examination by ultrasonography should be performed for the purpose of obtaining the greatest amount of information possible. It is important to determine the site of the lesion, which abdominal organs are inside the thorax, any alterations in amniotic fluid, fetal respiratory pattern, the degree of deviation of the mediastinum and the heart, cardiac compression and pulmonary volume, all of which constitute useful information for evaluating perinatal prognosis and helping define optimal prenatal and postnatal management (Johnson, 2005; Santos, et al., 2008).

$\mathrm{CDH}$ may be diagnosed by routine ultrasonography, or in some cases diagnosis is reached when the patient is submitted to a fetal morphological examination performed by a specialist between the $18^{\text {th }}$ and the $20^{\text {th }}$ weeks of pregnancy (Johnson, 2005; Santos, et al., 2008).

Ultrasonographic appearance varies depending on the type of $\mathrm{CDH}$ and in accordance with its location (Johnson, 2005; Santos, et al., 2008):

- Identification of the abdominal contents inside the thoracic cavity:

In cases of left diaphragmatic hernias, the presence of the stomach is viewed in the same plane used to evaluate the four chambers of the heart. When the hernia is located on the left, the stomach, the intestinal loops and the spleen may be found inside the thoracic cavity (Figure 1). If the defect is on the right, it is the liver that may be seen in the fetal thoracic cavity (Figures 2 and 3). It should be emphasized that hernias located on the right side may be diagnosed later in view of the similarity between the echogenic appearance of the hepatic parenchyma and that of the lung.

- $\quad$ Deviation of the mediastinum and heart with cardiac compression (Figures 1 and 2).

- Paradoxical movement of organs during fetal respiratory movement.

- Absence of normal integrity of the diaphragm, as seen on the longitudinal fetal plane.

- Polyhydramnios is generally associated with $\mathrm{CDH}$; however, this condition is rarely seen prior to 24 weeks.

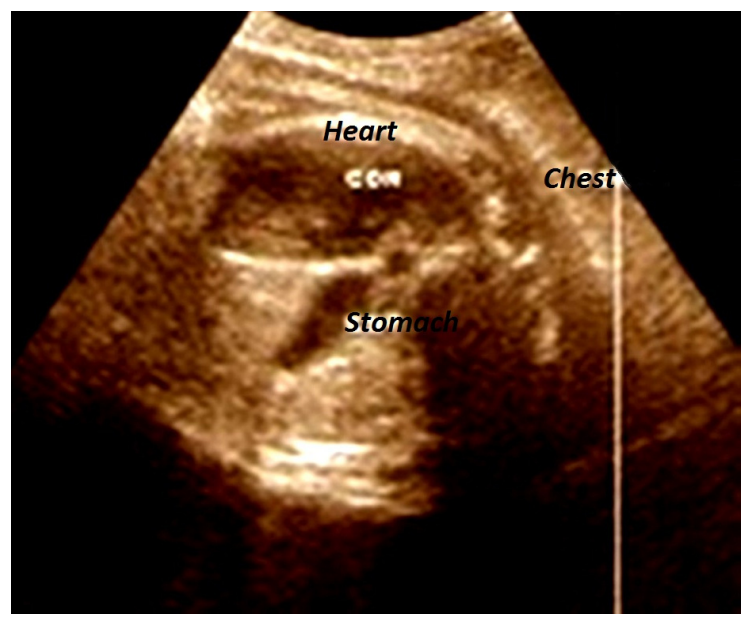

Fig. 1. Ultrasonographic cross-sectional image of the chest. Note the position of the heart deviated to the right and the presence of the stomach (gastric bubble) in the thorax (left diaphragmatic hernia). 


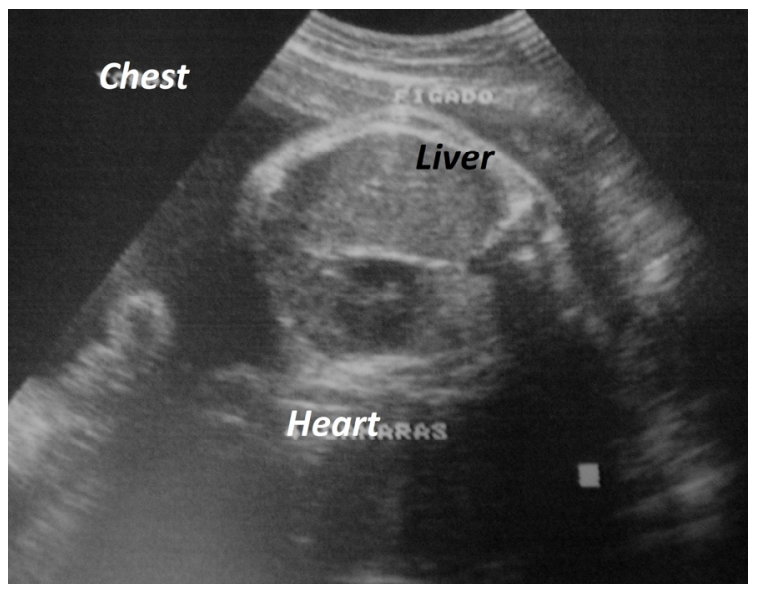

Fig. 2. Ultrasonographic cross-sectional image of the chest. Note the presence of the liver inside the chest, deviating the heart towards the left (right diaphragmatic hernia).

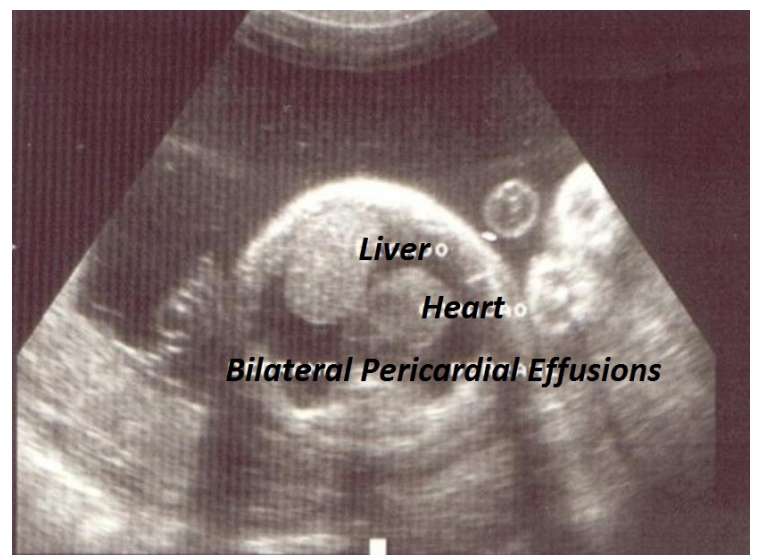

Fig. 3. Ultrasonographic cross-sectional image of the chest. Note the presence of the liver inside the chest, deviating the heart to the left (right diaphragmatic hernia) and the presence of bilateral pericardial effusions.

A normal prenatal ultrasound scan does not guarantee that $\mathrm{CDH}$ is not present. The condition may be diagnosed later, still prenatally by ultrasonography or neonatally, even when a previous scan carried out in the second trimester of pregnancy was normal (Bronshtein et al., 1995; Johnson, 2005). 2,3 Many studies have reported a false-positive rate of approximately $50 \%$, with rates being even higher in cases in which the defect has been diagnosed on the right side (Johnson, 2005; Lewis et al., 1997).

At the Instituto de Medicina Integral Prof. Fernando Figueira (IMIP), a diagnostic sensitivity of $93 \%$, specificity of $100 \%$ and a strong agreement of $96 \%$ were found with prenatal ultrasonography performed by fetal medicine specialists compared to perinatal results 
(Noronha Neto et al., 2009). It should be emphasized that that study included only patients who were submitted prenatally to ultrasonography in the fetal medicine unit. Patients who had not undergone ultrasonography in this service were excluded from the study. These results are in agreement with findings from other centers reporting diagnosis in almost $100 \%$ of cases with an isolated lesion after the $25^{\text {th }}$ week of pregnancy (Bronshtein et al., 1995; Johnson, 2005; Santos et al., 2008). Comparing the data obtained from different centers is difficult, since some centers describe only cases diagnosed prenatally, while others use postnatal data irrespective of the prenatal diagnosis (Johnson, 2005). There have also been literature reports on rare cases in which diagnosis is sometimes made late due to a delayed presentation of CDH symptoms (Koziarkiewicz \& Piaseczna-Piotrowska, 2011).

Three-dimensional ultrasonography may also be used for the diagnosis of $\mathrm{CDH}$. Its capacity to measure the volume of fetal structures such as the lung should be assessed in greater depth in order to evaluate fetal prognosis (Prendergast et al., 2011). Likewise, magnetic resonance imaging (MRI) may be used as a complement to conventional ultrasonography; however, its contribution has been more fully evaluated for the assessment of fetal prognosis (Amim et al., 2008; Costa et al., 2011; Souza, 2008).

\section{Associated abnormalities}

The presence of other congenital abnormalities associated with $\mathrm{CDH}$ is common, occurring in around 30-70\% of CDH cases diagnosed prenatally (Johnson, 2005; Zaiss et al., 2011) and 40\% of cases diagnosed in infancy (Cunniff et al., 1990; Johnson, 2005). Defects of the heart, face, gastrointestinal tract, kidney and neural tube may be associated with CDH (Santos et al., 2008). One study that included 362 fetuses with a diagnosis of $\mathrm{CDH}$ found an associated abnormality in 39.5\% ofcases. A total of 272 associated abnormalities were diagnosed; however, only $18.4 \%$ were diagnosed prenatally. That study reported a wide heterogeneity in these associated malformations, with cardiovascular defects being the most common (Zaiss et al., 2011). An association has also been reported between hypoplasia of the left ventricle and the presence of the liver in the thoracic cavity (Stressig et al., 2011).

In 25 to $34 \%$ of cases, there are associated chromosomal abnormalities, trisomy 21 and trisomy 18 being the most common (Johnson, 2005; Santos et al., 2008). Other more complex abnormalities also found include translocations (Johnson, 2005). In such situations, there are other associated structural abnormalities in $73 \%$ of cases, the most common being cardiac, skeletal, genitourinary defects and abnormalities of the central nervous system (Johnson, 2005; Santos et al., 2008).

\section{Differential diagnosis}

Differential diagnosis should be made with other thoracic cystic diseases such as congenital cystic adenomatoid malformation (CCAM) of the lung, bronchogenic cysts, tumors and neurenteric cysts (Santos et al., 2008). At this stage, fetal morphological examination is of crucial importance, and the patient can be submitted to threedimensional ultrasonography or MRI as a complement to conventional ultrasonography to clarify any remaining doubts. 


\section{Prenatal conduct}

Pregnancies with suspected or confirmed $\mathrm{CDH}$ should initially be referred to a specialist perinatal center for confirmatory tests and multidisciplinary follow-up (Santos et al., 2008). At the specialist perinatal center, fetal morphological examination by ultrasonography is used to confirm or refute the initial diagnosis and to provide details of the $\mathrm{CDH}$, or any other abnormalities (Santos et al., 2008).

The following factors regarding the $\mathrm{CDH}$, must be described: the side on which the diaphragmatic hernia is situated, which abdominal organs have been herniated into the thorax, the position of the liver and lung, the degree of deviation of the mediastinum, cardiac compression, the ratio between lung volume and head circumference, estimated lung volume and the volume of amniotic fluid (Johnson, 2005; Santos et al., 2008). Many methods to determine lung volume have been described (Johnson, 2005; Santos et al., 2008) and will be discussed in detail later. The characteristics of fetal respiration have also been evaluated to predict fetal outcome (Badalian et al., 1994; Johnson, 2005).Ultrasound scans should be performed between the $20-24^{\text {th }}$ weeks of pregnancy, 26- $28^{\text {th }}$ weeks and $32-34^{\text {th }}$ weeks to evaluate the $\mathrm{CDH}$, any associated abnormalities and to assess fetal growth and vitality (Santos et al., 2008).

Since cardiovascular defects constitute one of the principal abnormalities associated with CDH (Zaiss et al., 2011), a specialist fetal echocardiography is required to evaluate cardiac morphology (Johnson, 2005; Santos et al., 2008).

The parents should be referred for counseling with a multidisciplinary team composed of a fetal medicine specialist, an obstetrician and a neonatologist, as well as a pediatric surgeon specialized in thoracic surgery. Psychological support for the parents is crucial at this time (Johnson, 2005; Santos et al., 2008).

Due to the association of $\mathrm{CDH}$ with chromosomal abnormalities, fetal karyotyping is recommended, withe parental consent (Johnson, 2005; Santos et al., 2008). MRI can also be performed to detect the presence or absence of the liver in the thoracic cavity and to help determine fetal outcome (Amim et al., 2008; Costa et al., 2011; Souza, 2008; Terui et al., 2011). The principal causes of death are pulmonary hypoplasia and hypertension (Johnson, 2005; Santos et al., 2008). In an attempt to minimize these complications, Harrison et al. undertook open fetal surgery with disappointing results (Harrison et al., 1993). Intrauterine surgery under these circumstances remains controversial and alternative methods have been proposed such as fetal tracheal occlusion (Harrison et al., 1996). Although theoretically this technique appears promising, further clinical trials still need to be conducted before it can be performed routinely. It is important to emphasize that fetal surgery involves a significant risk of maternal morbidity and should only be undertaken when the expected improvement in fetal survival with this conduct exceeds the risks involved (Johnson, 2005).

More recently, fetal endoscopic tracheal occlusion (FETO) has been used and has proven to be a more viable and safer option. The most common complication is premature rupture of membranes; however, survival rates are apparently higher. Nevertheless, randomized clinical trials must be conducted before FETO can be confirmed as a viable option for increasing survival in these patients. The cases in which FETO may be useful 
are those involving fetuses with severe single $\mathrm{CDH}$, intrathoracic herniation of the liver and a lung-to-head ratio < 1 (Deprest et al., 2011; Luks, 2011; Peralta et al., 2011; Ruano et al., 2011).

FETO is a technique in which a balloon is introduced for tracheal occlusion through an endoscope with a $1.0 \mathrm{~mm}$ optical lens (fetoscopy). This tracheal occlusion permits pulmonary insufflation, thereby increasing intrathoracic pressure, which maintains the abdominal organs outside the thoracic cavity. To perform this procedure, the mother must be under epidural anesthesia and the fetus under intramuscular anesthesia (Ruano et al., 2011).

One study described FETO as a viable alternative for improving neonatal outcome in severe cases of CDH. A higher survival rate $(52.9 \%$ versus $5.6 \%$; $<0.01)$ and a lower rate of pulmonary hypertension $(47.1 \%$ versus $88.9 \%$; $p=0.01)$ were reported with the use of FETO. There was no statistically significant difference between the groups with respect to gestational age at delivery ( 35.6 weeks in the FETO group versus 37.5 weeks in the control group); however, it should be emphasized that the sample size was small ( $\mathrm{n}=35$ women) (Ruano et al., 2011).

In pregnancies between the 24- 34th weeks, antenatal corticosteroids is administered to accelerate lung maturity in accordance with the risk of prematurity and following routine procedure at each institution (betamethasone or dexamethasone) (Roberts \& Dalziel, 2006).

Spontaneous, full-term normal vaginal delivery is preferable; however, labor may be induced (Santos et al., 2008; Souza, 2008). Elective Cesarean section prior to the onset of labor is not recommended except when there is an obstetric indication. In fetuses that have had FETO, Cesarean section is indicated together with ex utero intrapartum therapy (EXIT). This is a Cesarean section in which complete placental circulation is maintained until removal of the balloon and the infant's airways are maintained pervious (Ruano et al., 2011; Nascimento et al., 2007).

\section{Prognosis}

When there is a confirmed prenatal diagnosis of $\mathrm{CDH}$, prognosis should be established. This is extremely difficult, particularly in view of the increasing advances in perinatology and pediatric surgery, which have contributed towards increasing the perinatal survival rate. Nevertheless, the most important factors in poor prognosis are the presence of associated malformations and the severity of pulmonary hypoplasia and hypertension, mortality rates remaining high in these cases despite the advances in neonatal intensive care with the introduction of extracorporeal membrane oxygenation (ECMO) (Santos et al., 2008).

The probability of survival, as reported in the literature, varies greatly, ranging from 14 to 78\% (Johnson, 2005; Okuyama et al., 2011; van den Hout et al., 2011). Various studies have suggested an increase in neonatal survival in patients with $\mathrm{CDH}$ resulting from an improvement in management and in medical advances (Okuyama et al., 2011; van den Hout et al., 2011). Nonetheless, it is important to emphasize the heterogeneity of these patients, which in most cases have been conducted in institutions that serve as referral centers. 
Therefore, it is important to discuss these survival rates, which should be established in population-based studies (Mah et al., 2011).

The most important indications of poor prognosis, as reported in the literature, are (Johnson, 2005; Santos et al., 2008):

- An association with chromosomal abnormalities and genetic syndromes.

- $\quad$ The presence of associated malformations.

- $\quad$ Suspected pulmonary hypoplasia.

- Large deviation of the mediastinum - defined as a deviation in which, in a crosssectional plane of the fetal thorax, the heart is found to be entirely in one or the other hemisphere, created by an imaginary line between the sternum and the spine.

- Polyhydramnios, a relatively late manifestation associated with poor prognosis.

- Presence of the liver in the thoracic cavity, which may be diagnosed by MRI.

- $\quad$ Early gestational age at diagnosis.

When the diagnosis is made prior to the $24^{\text {th }}$ week of pregnancy, the prognosis is unfavorable due to the stage of lung development at which the abnormality occurred. In this period, not only are the airways affected, causing pulmonary hypoplasia, but there is also a reduction in the number of blood vessels, resulting in postnatal pulmonary hypertension. In this case, mortality is very high, around $60-80 \%$ (Santos et al., 2008). Therefore, the earlier the prenatal diagnosis, the poorer the prognosis and the lower the probability of perinatal survival (Johnson, 2005; Santos et al., 2008).

Antenatal prediction of pulmonary hypoplasia is important since this diagnosis permits parents to be given appropriate counseling and selection to be carried out of those cases that would benefit from prenatal surgery. However, the issue remains a challenge for specialists in fetal medicine (Santos et al., 2008). The ability to predict perinatal outcome by prenatal ultrasonography when an isolated defect is present is limited, with many studies showing disappointing results (Johnson, 2005).

Various ultrasonographic parameters have been proposed to predict the probability of developing pulmonary hypoplasia. These include thoracic circumference, the calculated difference between the thoracic area and the heart area, lung area, thoracic circumference to abdominal circumference ratio, thoracic area to heart area ratio, the calculated difference between the thoracic area and the heart area to thoracic area ratio, lung-to-thorax transverse area ratio, and the lung-to-head ratio i.e. the ratio between the right lung area and head circumference (Johnson, 2005; Okuyama et al., 2011; Santos et al., 2008; Usui et al., 2011). The area of the right lung is obtained by multiplying the two greatest diameters of the lung. If the lung-to-head ratio is $\leq 1$, prognosis is very poor, even if ECMO is instituted at birth. If it is $>1.4$, prognosis is more favorable. Values between 1 and 1.4 were associated with a survival rate of $38 \%$ and in most cases ECMO was required. The infants who survived had a mean lung-to-head ratio of $1.4 \pm 0.33$ compared to $1.05 \pm 0.3$ in those who did not survive (Lipshutz et al., 1997).

Pulmonary blood flow has also been investigated for this purpose. A recent study used Doppler velocimetry of the pulmonary artery to predict prognosis and morbidity in fetuses with a diaphragmatic hernia that had been submitted to FETO. Doppler may also be used to define those fetuses that would benefit from this intrauterine therapy. The 
study concluded that following therapy, the combination of a relatively greater lung-tohead ratio and better pulmonary tissue perfusion improved the prediction of fetal survival (Cruz-Martinez, et al., 2011).

Therefore, authors suggest that fetuses with a congenital diaphragmatic hernia and a poor prognosis for postnatal treatment can be identified as those in whom part of the liver has been herniated into the thoracic cavity, those in whom diagnosis was made early (prior to the $25^{\text {th }}$ week), those with defects on the left side and the ones with a low lung-to-head ratio (Santos et al., 2008)..

It should be emphasized that, in general, all these methods represent efforts to predict pulmonary hypoplasia; however, the reproducibility of these measures has not been considered satisfactory (Johnson, 2005). It should also be noted that pulmonary hypoplasia probably begins prior to the $24^{\text {th }}$ week of pregnancy (at the end of the canalicular phase); therefore, all these parameters are only valid for a diagnosis of pulmonary hypoplasia that is already present and cannot be used to select patients who are candidates for a possible preventive intervention (Johnson, 2005).

MRI can be used to determine prognosis in fetuses with $\mathrm{CDH}$. One study included 12 fetuses with a prenatal diagnosis of $\mathrm{CDH}$ who were treated following birth and whose mothers had undergone MRI scanning in the 29th to 37th weeks of pregnancy. The ratio between the intensity of the signal in the lung and the intensity of the signal in the cerebrospinal fluid was calculated by analyzing the region of interest with T2 images. This ratio was found to be significantly higher in the infants who survived compared to those who died, and there was a statistically significant correlation with the duration of endotracheal intubation. The authors suggested that this ratio could be used to evaluate the degree of pulmonary hypoplasia (Terui et al., 2011). MRI has also been used to confirm the presence of the liver in the thoracic cavity, an important prognostic factor (Amim et al., 2008; Souza, 2008).

A study conducted with 153 fetuses with a diagnosis of $\mathrm{CDH}$ evaluated the lung-to-head ratio (area of the contralateral lung divided by the circumference of the head) using ultrasonography, while MRI was used to measure lung volume. Measurement of the lungto-head ratio using ultrasonography provided a good estimate of the fetal lung volume measurement provided by MRI. Additional parameters such as gestational age, the position of the liver and the side of the defect did not increase the accuracy of the calculation of the contralateral lung volume (Sandaite et al., 2011).

Another important point frequently discussed is that prognosis is directly related to neonatal care. One study found that neonatal survival increased from $67 \%$ to $88 \%$ following implementation of guidelines for the management of patients with $\mathrm{CDH}$. These new guidelines established the administration of nitric oxide in the delivery room, careful ventilation of the newborn infant, fewer criteria for the implementation of ECMO and surgical repair within an appropriate time. It should be emphasized that survival of the patients on ECMO increased from $20 \%$ to $82 \%$ (Antonoff et al., 2011). Another study conducted with 167 fetuses with $\mathrm{CDH}$ diagnosed prenatally also reported an improvement 
in survival following implementation of guidelines for the management of these patients (van den Hout et al., 2011).

The optimal time to perform surgical correction remains unclear: either after the condition of the infant has been stabilized or immediately within 24 hours. A major randomized, multicenter clinical trial is required to clarify this question (Moyer et al., 2011). Delaying surgery until the infant has been stabilized appears to be associated with better postsurgical outcome; however, this conduct may result in the infant dying prior to surgery in those more severe cases (Johnson, 2005).

In relation to nitric oxide, the available evidence appears to be in favor of the use of inhaled nitric oxide at an initial concentration of $20 \mathrm{ppm}$ for full-term newborns or those born near term with acute hypoxemic respiratory failure; however, there is few randomized clinical trials (RCT) supporting its use in patients with diaphragmatic hernia (Finer \& Barrington, 2011).

Modern methods of postnatal management appear to present varying results. ECMO and high-frequency oscillatory ventilation (HFOV) have shown disappointing results, with no great improvement in perinatal survival (Johnson, 2005). Although HFOV plus conventional ventilation has shown results that are similar to those found with ECMO. Up to the present time, there is insufficient evidence, based on RCT, to recommend its use (Henderson-Smart, et al., 2011). It should be noted that ECMO may be associated with long term development problems; therefore, careful follow-up is required (Johnson, 2005).

A meta-analysis made available in the Cochrane library, which includes four randomized clinical trials $(n=244)$, found that the use of ECMO in neonates with severe respiratory failure significantly improved survival, with a lower risk of death prior to discharge from hospital (RR 0.44; 95\%CI: 0.31 - 0.61) and a lower risk of death in the first year of life (RR 0.52; $95 \% \mathrm{CI}: 0.37-0.73)$. Nevertheless, there is insufficient evidence for its use in patients with CDH (Mugford et al., 2011).

\section{References}

[1] Amim, B.; Werner Jr, H.; Daltro, P.D.; Antunes, E.; Fazecas, T.; Rodrigues, L.; Guerra, F.; Marchiori, E.; Gaspareto, E.L. \& Domingues, R.C. (2008). O valor da ultrasonografia e da ressonância magnética fetal na avaliação das hérnias diafragmáticas. Radiol Bras, Vol.41, No.1, pp.1-6.

[2] Antonoff, M.B.; Hustead, V.A.; Groth, S.S. \& Schmeling, D.J. (2011). Protocolized management of infants with congenital diaphragmatic hernia: effect on survival. J Pediatr Surg, Vol.46, No.1, pp.39-46.

[3] Arraez-Aybar, L.A.; Gonzalez-Gomez, C.C. \& Torres-Garcia, A.J. (2009). MorgagniLarrey parasternal diaphragmatic hernia in the adult. Rev Esp Enferm Dig, Vol.101, No.5, pp.357-66.

[4] Badalian, S.S.; Fox, H.E.; Chao, C.R.; Timor-Tritsch, I.E. \& Stolar, C.J. (1994). Fetal breathing characteristics and postnatal outcome in cases of congenital diaphragmatic hernia. Am J Obstet Gynecol, Vol.171, No.4, pp.790-6. 
[5] Bronshtein, M.; Lewit, N.; Sujov, P.O.; Makhoul, I.R. \& Blazer S. (1995). Prenatal diagnosis of congenital diaphragmatic hernia: timing of visceral herniation and outcome. Prenat Diagn, Vol.15, No.8, pp.695-8.

[6] Burri, P.H. (1984). Fetal and post-natal development of the lung. Ann R Physiol, Vol.46, pp.R617-28.

[7] Caspers, K.M.; Oltean, C.; Romitti, P.A.; Sun, L.; Pober, B.R.; Rasmussen, A.S.; Yang, W.; Druschel, C. \& National Birth Defects Prevention Study. (2010). Maternal periconceptional exposure to cigarette smoking and alcohol consumption and congenital diaphragmatic hernia. Birth Defects Res A Clin Mol Teratol, Vol.88, No.12, pp.1040-9.

[8] Costa, F.; Kaganov, H.; O'Mahony, E.; Ng, J.; Fink, A.M. \& Palma-Dias, R. (2011). Diagnosis of diaphragmatic hernia with associated congenital lung lesions: contribution of fetal MRI. Fetal Diagn Ther, Vol.29, No.1, pp.:111-5.

[9] Cruz-Martinez, R.; Hernandez-Andrade, E.; Moreno-Alvarez, O.; Done, E.; Deprest, J. \& Gratacos, E. (2011). Prognostic value of pulmonary Doppler to predict response to tracheal occlusion in fetuses with congenital diaphragmatic hernia. Fetal Diagn Ther Vol.29, No.1, pp.18-24.

[10] Cunniff, C.; Jones, K.L. \& Jones, M.C. (1990). Patterns of malformations in children with congenital diaphragmatic defects. J Pediatr, Vol.116, No.2, pp.258-61.

[11] Deprest, J.; Nicolaides, K.; Done, E.; Lewi, P.; Barki, G.; Largen, E.; DeKoninck, P.; Sandaite, I.; Ville, Y.; Benachi, A.; Jani, J.; Amat-Roldan, I.; Gratacos, E. (2011). Technical aspects of fetal endoscopic tracheal occlusion for congenital diaphragmatic hernia. J Pediatr Surg, Vol.46, No.1, pp.22-32.

[12] Finer, N. \& Barrington, K.J. (2011). Nitric oxide for respiratory failure in infants born at or near term. Cochrane Database of Systematic Reviews. In: The Cochrane Library, Issue 08, Art. No. CD000399. DOI: 10.1002/14651858.CD000399.pub1.

[13] Fregnani, J.H.T.G.; Macéa, J.R. \& Barros, M.D. (2005). Cirurgia no hiato esofágico: a identificação correta das estruturas anatômicas. Rev Bras Videocir, Vol.3, No.1, pp.15-20.

[14] Harrison, M.R.; Adzick, N.S. \& Flake, A.W. (1993). Congenital diaphragmatic hernia: an unsolved problem. Semin Pediatr Surg, Vol.2, No.2. pp.109-12.

[15] Harrison, M.R.; Adzick, N.S. \& Flake, A.W. (1996). Correction of congenital diaphragmatic hernia in utero: VIII. Response of the hypoplastic lung to tracheal occlusion. J Pediatr Surg, Vol.31, pp.1339-48.

[16] Henderson-Smart, D.J.; De Paoli, A.G.; Clark, R.H. \& Bhuta, T. (2011). High frequency oscillatory ventilation versus conventional ventilation for infants with severe pulmonary dysfunction born at or near term. Cochrane Database of Systematic Reviews. In: The Cochrane Library, Issue 08, Art. No. CD002974. DOI: 10.1002/14651858.CD002974.pub.

[17] Johnson, P. (2005). Malformações torácicas, In: Medicina Fetal Fundamentos e Prática Clínica [Fetal Medicine: Basic Science and Clinical Practice] (1st Ed), Rodeck, C.H. \& Whittle, M.J, (Editors), pp. 651-63, Revinter, ISBN 978-85-7309-857-0, Rio de Janeiro, Brasil. 
[18] Kessler, R.; Pett, S. \& Wernly, J. (1991). Peritoneopericardial diaphragmatic hernia discovered at coronary bypass operation. Ann Thorac Surg; 52: 562-3.

[19] Koziarkiewicz, M. \& Piaseczna-Piotrowska, A. (2011). Pózna manifestacja wrodzonej przepukliny przeponowej - opis przypadku [Late manifestation of congenital diaphragmatic hernia - case report]. Med Wieku Rozwoj, Vol.15, No.1, pp.106-9.

[20] Lewis, D.A.; Reickert, C.; Bowserman, R.; Hirschl, R.B. (1997). Prenatal ultrasonography frequently fails to diagnose congenital diaphragmatic hernia. J Pediatr Surg, Vol.32, No.2, pp.352-6.

[21] Lipshutz, G.S.; Albanese, C.T.; Feldestein, V.A.; Jennings, R.W.; Housley, H.T.; Beech, R.; Farrell, J.A. \& Harrison MR. (1997). Prospective analysis of lung-to-head ratio predicts survival for patients with prenatally diagnosed congenital diaphragmatic hernia. J Pediatr Surg, Vol.32, No.11, pp.1634-6.

[22] Luks, F.I. (2011). New and/or improved aspects of fetal surgery. Prenat Diagn, Vol.31, No.3, pp.252-8.

[23] Mah, V.K.; Chiu, P. \& Kim, P.C. (2011). Are we making a real difference? Update on 'hidden mortality' in the management of congenital diaphragmatic hernia. Fetal Diagn Ther, Vol.29, No.1, pp.40-5.

[24] Manni, M.; Heydanus, R.; Den-Hollander, N.S.; Tewart, P.A.; De Vogelaere, C. \& Wladimiroff, J.W. (1994). Prenatal diagnosis of congenital diaphragmatic hernia: a retrospective analysis of 28 cases. Prenat Diagn, Vol.14, pp.187-90.

[25] Moyer, V.A.; Moya, F.R.; Tibboel, D.; Losty, P.D.; Nagaya, M. \& Lally, K.P. (2011). Late versus early surgical correction for congenital diaphragmatic hernia in newborn infants. Cochrane Database of Systematic Reviews. In: The Cochrane Library, Issue 08, Art. No. CD001695. DOI: 10.1002/14651858.CD001695.pub3.

[26] Mugford, M.; Elbourne, D. \& Field D. (2011). Extracorporeal membrane oxygenation for severe respiratory failure in newborn infants. Cochrane Database of Systematic Reviews. In: The Cochrane Library, Issue 08, Art. No. CD001340. DOI: 10.1002/14651858.CD001340.pub1.

[27] Narayan, H.C.R.; Barrow, M.; Mckeever, P. \& Neale, E. (1993). Familial congenital diaphragmatic hernia: prenatal diagnosis, management and outcome. Prenat Diagn, Vol.13, No.10, pp.893-901.

[28] Nascimento, G.C.; Souza, A.S.R.; Lima, M.M.S.; Guerra, G.V.; Meneses, J.A.; Cardoso, A.S. \& Azevedo, K.S. (2007). Estratégia de conduta intraparto no teratoma cervical congênito: procedimento EXIT (Tratamento extra-útero intraparto). Act Med Port, Vol.20, pp.221-7.

[29] Noronha Neto, C.; Souza, A.S.R.; Moraes Filho, O.B. \& Noronha, A.M.B. (2009). Validação do diagnóstico ultrassonográfico de anomalias fetais em centro de referência. Rev Assoc Med Bras, Vol.55, No.5, pp.541-6.

[30] Okuyama, H.; Kitano, Y.; Saito, M.; Usui, N.; Morikawa, N.; Masumoto, K.; Takayasu, H.; Nakamura, T.; Ishikawa, H.; Kawataki, M.; Hayashi, S.; Inamura, N.; Nose, K. \& Sago, H. (2011). The Japanese experience with prenatally diagnosed congenital diaphragmatic hernia based on a multi-institutional review. Pediatr Surg Int, Vol.27, No.4, pp.373-8. 
[31] Peralta, C.F.; Sbragia, L.; Bennini, J.R.; Braga, F.A.A.; Sampaio, R.M.; Machado, R.I.R. \& Barini, R. (2011). Fetoscopic endotracheal occlusion for severe isolated diaphragmatic hernia: initial experience from a single clinic in Brazil. Fetal Diagn Ther, Vol.29, No.1, pp.71-7.

[32] Prendergast, M.; Rafferty, G.F.; Davenport, M.; Persico, N.; Jani, J.; Nicolaides, K. \& Greenough, A. (2011). Three-dimensional ultrasound fetal lung volumes and infant respiratory outcome: a prospective observational study. BJOG, Vol.118, No.5, pp.608-14.

[33] Roberts, D. \& Dalziel, S. (2006). Antenatal corticosteroids for accelerating fetal lung maturation for women at risk of preterm birth. Cochrane Database Syst Rev; 3:CD004454.

[34] Ruano, R.; Duarte, A.S.; Pimenta, E.J.; Takashi, E.; da Silva, M.M.; Tannuri, U. \& Zugaib, M. (2011). Comparison between fetal endoscopic tracheal occlusion using a 1.0-mm fetoscope and prenatal expectant management in severe congenital diaphragmatic hernia. Fetal Diagn Ther, Vol.29, No.1, pp.64-70.

[35] Sandaite, I.; Claus, F.; De Keyzer, F.; Done, E.; Van Mieghem, T.; Gucciardo, L.; DeKoninck, P.; Jani, J.; Cannie, M. \& Deprest, J.A. (2011). Examining the relationship between the lung-to-head ratio measured on ultrasound and lung volumetry by magnetic resonance in fetuses with isolated congenital diaphragmatic hernia. Fetal Diagn Ther, Vol.29, No.1, pp.80-7.

[36] Santos, L.C.; Figueiredo, S.R.; Souza, A.S.R. \& Marques M. (2008). Medicina Fetal (1 ${ }^{\text {st }}$ Ed), Medbook, ISBN 978-85-99977-19-4, Rio de Janeiro, Brasil.

[37] Sociedade Brasileira de Anatomia. (2001). Terminologia Anatômica. Terminologia

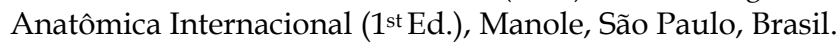

[38] Souza, A.S.R. (2008). O valor da ultra-sonografia e da ressonância magnética fetal na avaliação das hérnias diafragmáticas. Radiol Bras, Vol.41, No.3, pp.VII-VIII.

[39] Stressig, R.; Fimmers, R.; Eising, K.; Gembruch, U. \& Kohl, T. (2011). Intrathoracic herniation of the liver ('liver-up') is associated with predominant left heart hypoplasia in human fetuses with left diaphragmatic hernia. Ultrasound Obstet Gynecol, Vol.37, No.3, pp.272-6.

[40] Terui, K.; Omoto, A.; Osada, H.; Hishiki, T.; Saito, T.; Sato, Y; Nakata, M.; Komatsu, S.; Ono, S. \& Yoshida, H. (2011). Prediction of postnatal outcomes in congenital diaphragmatic hernia using MRI signal intensity of the fetal lung. J Perinatol, Vol.31, No.4, pp.269-73.

[41] Usui, N.; Kitano, Y.; Okuyama, H.; Saito, M.; Morikawa, N.; Takayasu, H.; Nakamura, T.; Hayashi, S.; Kawataki, M.; Ishikawa, H.; Nose, K.; Inamura, N.; Masumoto, K. \& Sago, H. (2011). Reliability of the lung to thorax transverse area ratio as a predictive parameter in fetuses with congenital diaphragmatic hernia. Pediatr Surg Int, Vol.27, No.1, pp.39-45.

[42] van den Hout, L.; Schaible, T.; Cohen-Overbeek, T.E.; Hop, W.; Siemer, J.; van de Ven, K.; Wessel, L.; Tibboel, D. \& Reiss, I. (2011). Actual outcome in infants with congenital diaphragmatic hernia: the role of a standardized postnatal treatment protocol. Fetal Diagn Ther, Vol.29, No.1, pp.55-63. 
[43] Zaiss, I.; Kehl, S.; Link, K.; Neff, W.; Schaible, T.; Sütterlin, M. \& Siemer, J. (2011). Associated malformations in congenital diaphragmatic hernia. Am J Perinatol, Vol.28, No.3, pp.211-8.

[44] Yamagami, T.; Yoshimatsu, R.; Matsushima, S.; Tanaka, O.; Miura, H. \& Nishimura, T. (2011). Diaphragmatic hernia after radiofrequency ablation for hepatocellular carcinoma. Cardiovasc Intervent Radiol, Vol.34, No.Suppl 2, pp.S175-7.

[45] Wat, M.J.; Veenma, D.; Hogue, J.; Holder, A.M.; Yu, Z.; Wat, J.J.; Hanchard, N.; Shchelochkov, O.A.; Fernandes, C.J.; Johnson, A.; Lally, K.P.; Slavotinek, A.; Danhaive, O.; Schaible, T.; Cheung, S.W.; Rauen, K.A.; Tonk, V.S.; Tibboel, D.; de Klein, A. \& Scott, D.A. (2011). Genomic alterations that contribute to the development of isolated and non-isolated congenital diaphragmatic hernia. J Med Genet, Vol.48, No.5, pp.299-307. 
(C) 2012 The Author(s). Licensee IntechOpen. This is an open access article distributed under the terms of the Creative Commons Attribution 3.0 License, which permits unrestricted use, distribution, and reproduction in any medium, provided the original work is properly cited. 